\title{
STRATEGI PENINGKATAN DAYA SAING SEKTOR JASA PARIWISATA INDONESIA: STUDI KASUS JASA PARIWISATA DANAU TOBA DAN BALI
}

\section{STRATEGIES FOR INCREASING COMPETITIVENESS OF INDONESIA'S TOURISM SERVICES SECTOR: CASE STUDY OF LAKE TOBA AND BALI TOURISM SERVICES}

\author{
Widyastutik $^{*}$, Iskandar Panjaitan**), Florika Malau**), dan Youshy Fahreiza**) \\ ${ }^{*}$ Departemen Ilmu Ekonomi, Fakultas Ekonomi dan Manajemen, IPB University \\ Jl. Agatis Kampus IPB Darmaga, Bogor 16680, Indonesia \\ **) Direktorat Jenderal Perundingan Perdagangan Internasional, Kementerian Perdagangan \\ Jl. M.I. Ridwan Rais No. 5 Jakarta 10110, Indonesia
}

\begin{abstract}
The tourism sector contributed as the third largest foreign exchange in 2017 after coal and palm commodities that amounted to 14.86 billion US \$. In another condition, tourism services export's growth is lower than other sector. This research is aiming to (1) analyze tourism service performance, (2) Develop a strategy to increase the competitiveness of Indonesia's tourism sector with a case study of the tourism service sector in Lake Toba and Bali. Bali is chosen as a research location because it becomes a benchmark for the development of 10 destination priorities for Indonesia's tourism, while Lake Toba becomes one of the priorities for the development of increased tourist visits to Indonesia. This research uses primary and secondary data. Primary data are obtained from distributing questionnaires in in-depth interviews and FGDs. While secondary data come from the Central Statistics Agency, Bank of Indonesia, The World Economic Forum, and The World Bank. The analytical method used is Analytical Hierarchy Process (AHP). The results show that tourists visiting Indonesia are dominated by countries in the ASEAN and other Asia Pacific regions such as Malaysia, China, Singapore, Australia, Timor Leste, Japan, India, and South Korea. Furthermore, other partner countries included in the Top 15 are the United Kingdom, the United States, France, Germany, and the Netherlands. The priority strategy for increasing competitiveness of Indonesia's tourism services case studies Toba Lake and Bali are government facilitation and synergy between Ministries/Institutions followed by a strategy to create a business climate with friendly regulations and finally a strategy to strengthen tourism support infrastructure.
\end{abstract}

Keywords: competitiveness, services export's, tourism service sector, AHP

\begin{abstract}
Abstrak: Sektor pariwisata menyumbang devisa terbesar ketiga pada tahun 2017 setelah komoditas batu bara dan sawit yaitu sebesar 14.86 miliar US\$. Namun, pertumbuhan ekspor jasa pariwisata relatif rendah dibandingkan dengan sektor lain. Penelitian ini bertujuan (1) menganalisis kinerja jasa pariwisata, (2) menyusun strategi peningkatan daya saing sektor pariwisata dengan studi kasus sektor jasa pariwisata di Danau Toba dan Bali. Bali dipilih sebagai lokasi penelitian karena menjadi benchmark bagi pengembangan 10 prioritas destinasi utama pariwisata Indonesia sedangkan Danau Toba sendiri menjadi salah satu prioritas bagi pengembangan peningkatan kunjungan wisata ke Indonesia. Jenis data pada penelitian ini adalah data primer dan sekunder. Data primer diperoleh melalui penyebaran kuesioner melalui indepth interview dan FGD. Sedangkan data sekunder bersumber dari BPS (Badan Pusat Statistik), BI (Bank Indonesia), WEF (World Economic Forum), dan World Bank. Metode analisis dengan menggunakan AHP (Analytical Hierarchy Process). Hasil penelitian menunjukkan wisatawan yang berkunjung ke Indonesia didominasi oleh negara di kawasan ASEAN dan Asia Pasifik lainnya seperti Malaysia, China, Singapura, Australia, Timor Leste, Jepang, India, dan Korea Selatan. Selain itu, negara mitra lainnya yang masuk kedalam Top 15 adalah Inggris, Amerika Serikat, Perancis, Jerman, dan Belanda. Prioritas strategi peningkatan daya saing sektor jasa pariwisata Indonesia studi kasus tempat wisata Danau Toba dan Bali adalah fasilitasi pemerintah dan sinergitas antara Kementerian/Lembaga disusul strategi menciptakan iklim bisnis dengan regulasi yang ramah dan terakhir strategi penguatan infrastruktur pendukung pariwisata.
\end{abstract}

Kata kunci: daya saing, ekspor jasa, sektor jasa pariwisata, AHP

\footnotetext{
${ }^{1}$ Alamat korespondensi:

Email: widyastutik@apps.ipb.ac.id
} 


\section{PENDAHULUAN}

Pada landscape ekonomi modern, negara yang maju akan didominasi oleh peran yang besar dari sektor jasa. Berdasarkan Worldbank (2019), kontribusi sektor jasa terhadap GDP dunia pada tahun 2017 pada kelompok negara berpendapatan rendah sebesar 39,3 persen dan 69,9 persen berpendapatan tinggi. Pada level domestik, perkembangan sektor jasa terhadap GDP Indonesia dan penyerapan tenaga kerja selama periode tahun 2005 sampai dengan 2017 (Gambar 1). Dari pendekatan nilai tambah, kontribusi sektor jasa meningkat sebesar 3,3 persen dari GDP, yaitu 40,3 pada tahun 2005 menjadi 43,6 persen pada tahun 2017, tetapi kontribusinya terhadap penyerapan tenaga kerja relative tinggi. Pada tahun 2005 sebesar 37,2 persen meningkat menjadi 47,1 persen. Hal ini mengindikasikan bahwa produktivitas sektor jasa Indonesia masih rendah.
Apabila melihat data pada Tabel 1 lebih lanjut, sektor jasa yang memiliki kontribusi tertinggi terhadap ekspor jasa Indonesia, yaitu sektor jasa perjalanan dan pariwisata. Hal ini menguatkan bahwa sektor jasa perjalanan dan pariwisata merupakan sektor yang paling potensial untuk pengembangan ekspor jasa Indonesia. Sektor pariwisata menyumbang devisa terbesar ketiga pada tahun 2017 di bawah komoditas batubara dan sawit yaitu sebesar 14,86 miliar US\$. Target sektor pariwisata pada tahun 2019 adalah jumlah kunjungan 20 juta, penerimaan devisa sebesar Rp240 triliun dan sumbangan terhadap GDP Indonesia sebesar 8 persen. Meskipun sektor jasa perjalanan dan pariwisata memiliki kontribusi yang tinggi, berdasarkan Tabel 1 . dinamika pertumbuhan ekspor tertinggi ditunjukkan oleh sektor jasa keuangan $(0,88$ persen $)$, jasa konstruksi $(0,52$ persen $)$, serta jasa personal, kultural, dan rekreasi (0,52 persen).

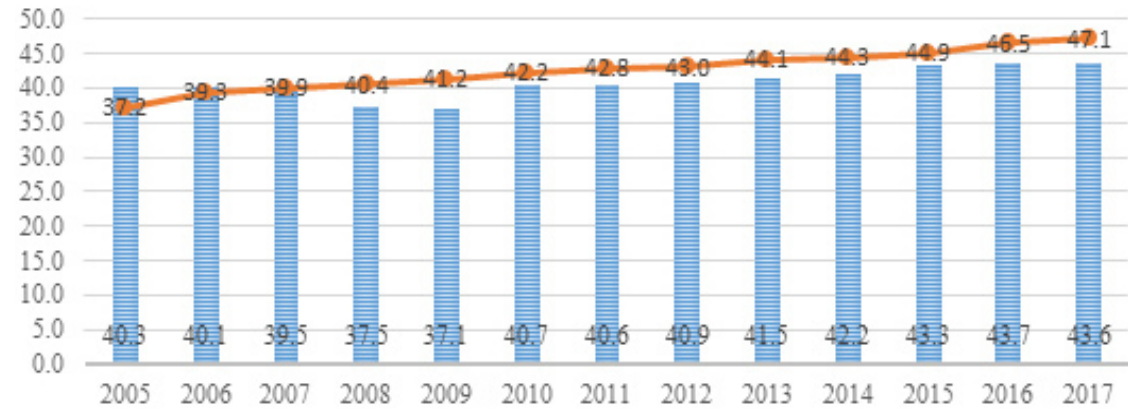

Gambar 1. Kontribusi sektor jasa terhadap GDP dan kesempatan kerja periode tahun 2005-2017 (World Bank (WDI), 2019)

Tabel 1. Ekspor jasa Indonesia, tahun 2015-2017(dalam juta USD)

\begin{tabular}{lcccc}
\hline Sektor & 2015 & 2016 & 2017 & $\begin{array}{c}\text { Pertumbuhan } \\
2016-2017(\%)\end{array}$ \\
\hline Jasa Perjalanan dan Pariwisata & & & & 0,12 \\
Jasa bisnis & $10.760,95$ & $11.205,66$ & $12.519,99$ & $-0,03$ \\
Jasa Transportasi & $4.917,39$ & $5.358,54$ & $5.207,14$ & $-0,02$ \\
Jasa telekomunikasi, komputer, dan informasi & $3.456,21$ & $3.571,95$ & $3.504,90$ & $-0,05$ \\
Jasa pemerintah & 971,12 & 970,37 & 922,33 & 0,07 \\
Jasa keuangan & 631,84 & 678,20 & 722,60 & 0,88 \\
Jasa konstruksi & 247,74 & 336,03 & 630,67 & 0,64 \\
Jasa manufaktur & 378,70 & 225,69 & 369,25 & 0,01 \\
Jasa pemeliharaan dan perbaikan & 355,56 & 350,51 & 353,97 & $-0,59$ \\
Jasa personal, kultural, dan rekreasi & 283,54 & 410,77 & 169,76 & 0,52 \\
Jasa asuransi dan dana pensiun & 111,49 & 88,89 & 135,14 & 0,03 \\
Biaya penggunaan kekayaan intelektual & 54,24 & 80,22 & 82,65 & 0,07 \\
Total ekspor jasa & 52,09 & 46,70 & 49,80 & 0,06 \\
\hline
\end{tabular}

Sumber: Bank Indonesia (2018) 
Tidak hanya masalah pertumbuhan ekspornya yang relatif rendah tetapi juga indeks daya saing sektor jasa perjalanan dan pariwisata ini juga relatif lebih rendah disamping peringkatnya tertinggal jauh dibandingkan peer countries seperti terlihat pada Tabel 2. Pada tahun 2019, pemerintah telah menetapkan prioritas dalam pengembangan konektivitas, terutama di sektor penerbangan, pengembangan terintegrasi dari 10 prioritas utama dan penciptaan ribuan homestay, terutama di Danau Toba (Sumatra Utara), Tanjung Kelayang (Belitung), Tanjung Lesung (Banten), Kepulauan Seribu (Jakarta), lingkungan Borobudur (Jawa Tengah), daerah pegunungan Bromo-Tengger (Jawa Timur), Mandalika (Lombok), Labuan Bajo (Flores), dan Pulau Morotai (Maluku Utara).

Hal ini tentunya menjadi tantangan bagi sektor jasa pariwisata baik dari sisi pebisnis (pelaku usaha), pemerintah dan stakeholder terkait untuk meningkatkan daya saingnya terutama dengan semakin meningkatnya keterbukaan ekonomi/globalisasi. Penelitian terdahulu lebih fokus pada daya saing seperti Sabahan (2017) dengan studi kasus daya saing pariwisata Kabupaten Sambas. Masruroh dan Nurhayati (2016) melakukan penelitian mengenai strategi pengembangan pariwisata dalam rangka peningkatan PAD Kabupaten Kuningan, tetapi lebih kualitatif seperti halnya studi Aulia dan Farah (2017) dengan menggunakan SWOT. Prasetyaningrum dan Sari (2019) menggunakan AHP untuk menganalisis pengambilan keputusan dalam menentukan pemilihan destinasi tempat wisata Yogyakarta untuk wisatawan mancanegara non Asia. Penelitian untuk kasus negara Amerika Latin, dilakukan oleh Molinar et al. (2017) lebih fokus pada persepsi turis mengenai daya saing destinasi wisata di Meksiko dengan metode analisis faktor. Sementara itu penelitian Stankova dan Vasenska (2017) menggunakan model COMPETITIVTOUR membandingkan daya saing antara Portugal dan
Spanyol. Penelitian ini mengkuantitatifkan data kualitatif dengan menggunakan metode Analytical Hierarchy Process (AHP). Terkait dengan hal tersebut, maka penelitian ini bertujuan (1) Menganalisis kinerja jasa pariwisata berdasarkan kunjungan wisatawan mancanegara ke Indonesia, (2) Menyusun strategi peningkatan daya saing sektor pariwisata Indonesia dengan studi kasus sektor jasa pariwisata di Danau Toba dan Bali. Danau Toba dan Bali dipilih sebagai lokasi penelitian mengingat Bali menjadi benchmark bagi pengembangan 10 prioritas destinasi utama pariwisata Indonesia sedangkan Danau Toba menjadi salah satu prioritas bagi pengembangan peningkatan kunjungan wisata ke Indonesia.

\section{METODE PENELITIAN}

Provinsi Sumatera Utara yang diwakili destinasi wisata Danau Toba dan Provinsi Bali dianggap representative sebagai lokasi penyedia jasa pariwisata di Indonesia. Selain penyebaran kuesioner juga dilakukan Focus Group Discussion (FGD) untuk memperoleh informasi mengenai peningkatan daya saing jasa pariwisata. Penyebaran kuesioner dilakukan pada bulan Oktober sampai dengan November tahun 2018. FGD diselenggarakan di Bali pada tanggal November 2018. Stakeholder yang diundang untuk FGD Bali terdiri dari Kepala Pelabuhan Benoa Bali; General Manager Bandar Udara Ngurah Rai Bali; Kepala Dinas Pariwisata Propinsi Bali; Kepala Dinas Perdagangan Propinsi Bali; Universitas Udayana; Sekolah Tinggi Pariwisata Bali; Perhimpunan Hotel dan Restoran Indonesia Cabang Bali; Lembaga Sertifikasi Usaha Pariwasta Bali; Perwakilan Pengusaha Jasa Hotel di Bali; dan Perwakilan Jasa Travel di Bali. Ringkasan lokasi dan responden dalam penelitian ini disajikan pada Tabel 3.

Tabel 2. Perkembangan skor dan Ranking Travel and Tourism Competitiveness Index (TTCI) Berdasarkan Negara, Tahun 2009-2019

\begin{tabular}{|c|c|c|c|c|c|c|c|c|c|c|c|c|}
\hline \multirow[t]{2}{*}{ Negara } & \multicolumn{6}{|c|}{ Skor } & \multicolumn{6}{|c|}{ Ranking } \\
\hline & 09 & 11 & 13 & 15 & 17 & 19 & 09 & 11 & 13 & 15 & 17 & 19 \\
\hline Singapura & 5,24 & 5,23 & 5,23 & 4,86 & 4,85 & 4,80 & 10 & 10 & 10 & 11 & 13 & 17 \\
\hline Malaysia & 4,71 & 4,59 & 4,70 & 4,41 & 4,50 & 4,50 & 32 & 35 & 34 & 25 & 26 & 29 \\
\hline Thailand & 4,45 & 4,47 & 4,47 & 4,26 & 4,38 & 4,50 & 39 & 41 & 43 & 35 & 34 & 31 \\
\hline Indonesia & 3,79 & 3,96 & 4,03 & 4,04 & 4,16 & 4,30 & 81 & 74 & 70 & 50 & 42 & 40 \\
\hline Vietnam & 3,70 & 3,90 & 3,95 & 3,60 & 3,78 & 3,90 & 89 & 80 & 80 & 75 & 67 & 63 \\
\hline
\end{tabular}

Sumber: WEF (2019). 
Tabel 3. Lokasi dan responden penelitian

\begin{tabular}{ll}
\hline Lokasi & Responden \\
\hline Sumatera & Hotel di Medan, Brastagi dan Parapat \\
Utara & Pengelola Objek Wisata (Badan Otorita Pengembangan Danau Toba, Pemandian Air Panas di daerah Brastagi) \\
& Turis asing dan domestik \\
& Pelabuhan Belawan \\
& Bandar Udara Kualanamu \\
Bali & Hotel di Kabupaten Badung \\
& Pengelola Objek Wisata (Uluwatu, Garuda Wisnu Kencana, Tanah Lot) \\
& Turis asing dan domestik \\
& Pelabuhan Belawan \\
& Bandar Udara Ngurah Rai \\
\hline
\end{tabular}

Data yang digunakan dalam penelitian merupakan gabungan data primer dan sekunder. Data primer dikumpulkan melalui wawancara dengan menggunakan kuesioner secara mendalam (in-depth interview) terhadap informan kunci di Destinasi Wisata Sumatera Utara yaitu Danau Toba dan Bali yang memiliki potensi di sektor jasa pariwisata. Selain in-depth interview juga dilakukan FGD yang diselenggarakan di Bali. Selain data primer, penelitian ini juga menggunakan data sekunder yang bersumber dari BPS (Badan Pusat Statistik), BI (Bank Indonesia), WEF (World Economic Forum), dan World Bank.

Dalam penelitian ini digunakan metode analisis AHP. Pendekatan AHP hampir identik dengan model perilaku politis, yaitu model keputusan (individual) dengan menggunakan pendekatan kolektif dari proses pengambilan keputusan. AHP dikembangkan oleh Saaty (1994) yang dapat memecahkan masalah kompleks dengan aspek atau kriteria yang cukup banyak. Metode AHP digunakan oleh beberapa penelitian terkait sektor jasa pariwisata diantaranya Hareen (2016) mengenai penentuan prioritas objek wisata yang akan dikembangkan di Kabupaten Bojonegoro dan Pambudi (2018) untuk kasus pengambilan keputusan mengenai destinasi wisata air bagi turis di Kota Bogor. Kompleksitas disebabkan oleh struktur masalah yang belum jelas, ketidakpastian persepsi pengambil keputusan serta ketidakpastian data statistik yang akurat atau bahkan tidak ada sama sekali. Metode AHP menggunakan responden yang ahli di bidangnya, misalnya dinas terkait, pelaku usaha dan akademisi. Tabel 4 menunjukkan skala penilaian perbandingan pasangan yang digunakan dalam metode AHP.
Sebelumnya akan diuraikan langkah-langkah dalam metode AHP menurut Saaty (1994) yang meliputi: Menentukan masalah dan solusi yang diinginkan; Membuat struktur hierarki yang diawali dengan tujuan umum dilanjutkan dengan sub-sub tujuan, kriteria dan kemungkinan alternatif-alternatif pada tingkatan kriteria yang paling bawah; Membuat matriks perbandingan berpasangan yang menggambarkan kontribusi relatif atau pengaruh setiap elemen terhadap masing-masing tujuan atau kriteria yang setingkat di atasnya. Perbandingan dilakukan berdasarkan judgement dari pengambil keputusan dengan menilai tingkat kepentingan suatu elemen dibandingkan elemen lainnya; Melakukan perbandingan berpasangan sehingga memperoleh judgement seluruhnya sebanyak $\mathrm{n} \times[(\mathrm{n}-1)] / 2$ buah, di mana $\mathrm{n}$ adalah jumlah elemen yang dibandingkan; Menghitung eigenvalue dengan menguji konsistensinya. Jika tidak konsisten, maka pengambilan data akan diulang; Menghitung langkah 3,4,5 untuk seluruh tingkat hierarki; Menghitung eigenvector dari setiap matriks perbandingan berpasangan. Nilai eigenvector merupakan bobot setiap elemen. Langkah ini bertujuan mensintesis judgement dalam penentuan prioritas elemen-elemen pada tingkat hierarki terendah sampai pencapaian tujuan; Memeriksa konsistensi hierarki. Jika nilainya lebih besar dari 10\% maka penilaian data judgement harus diperbaiki.

Hipotesis dalam penelitian ini adalah prioritas strategi peningkatan daya saing jasa pariwisata studi kasus Danau Toba dan Bali adalah fasilitasi pemerintah dan sinergitas antara $\mathrm{K} / \mathrm{L}$ diikuti regulasi yang ramah dan terakhir strategi penguatan infrastruktur pendukung pariwisata. 
Sektor pariwisata menyumbang devisa terbesar ketiga pada tahun 2017, tetapi pertumbuhan ekspor jasa pariwisata relatif rendah dibandingkan dengan sektor lain. Selain itu, indeks daya saing sektor jasa perjalanan dan pariwisata Indonesia juga relatif lebih rendah, disamping peringkatnya tertinggal jauh dibandingkan peer countries. Terkait dengan permasalahan tersebut, penelitian ini bertujuan (1) menganalisis kinerja jasa pariwisata, (2) menyusun strategi peningkatan daya saing sektor pariwisata dengan studi kasus sektor jasa pariwisata di Danau Toba dan Bali. Secara grafis dapat dilihat pada Gambar 2.

\section{HASIL}

\section{Kinerja Jasa Pariwisata Berdasarkan Kunjungan Wisatawan Mancanegara}

Berdasarkan negara asal, dapat diidentifikasi bahwa kinerja perdagangan jasa pariwisata berdasarkan jumlah kunjungan wisatawan mancanegara di tahun 2017 (proksi dari mode 2, consumption abroad) didominasi oleh negara di kawasan ASEAN dan Asia Pasifik lainnya seperti Malaysia, China, Singapura, Australia, Timor Leste, Jepang, India, dan Korea Selatan. Negara Malaysia dan China masing-masing merepresentasikan share wisatawan mancanegara terbesar (15 persen) dengan jumlah wisatawan sebesar 2,1 juta di tahun 2017 (Gambar 3).

Tabel 4. Skala penilaian perbandingan pasangan

\begin{tabular}{|c|c|c|}
\hline Intensitas kepentingan & Keterangan & Penjelasan \\
\hline 1 & Kedua elemen sama pentingnya & $\begin{array}{l}\text { Dua elemen mempunyai pengaruh yang sama besar } \\
\text { terhadap tujuan }\end{array}$ \\
\hline 3 & $\begin{array}{l}\text { Elemen yang satu sedikit lebih penting } \\
\text { daripada elemen yang lainnya }\end{array}$ & $\begin{array}{l}\text { Pengalaman dan penilaian sedikit menyokong satu } \\
\text { elemen dibandingkan elemen lainnya }\end{array}$ \\
\hline 5 & $\begin{array}{l}\text { Elemen yang satu lebih penting } \\
\text { daripada elemen lainnya }\end{array}$ & $\begin{array}{l}\text { Pengalaman dan penilaian sangat kuat menyokong satu } \\
\text { elemen dibandingkan elemen lainnya }\end{array}$ \\
\hline 7 & $\begin{array}{l}\text { Satu elemen jelas/mutlak lebih penting } \\
\text { daripada elemen lainnya }\end{array}$ & $\begin{array}{l}\text { Satu elemen yang kuat disokong dan dominan terlihat } \\
\text { dalam praktek }\end{array}$ \\
\hline 9 & $\begin{array}{l}\text { Satu elemen mutlak penting } \\
\text { daripada elemenlainnnya }\end{array}$ & $\begin{array}{l}\text { Bukti yang mendukung elemen yang satu tehadap } \\
\text { elemen lain memiliki tingkat penegasan tertinggi yang } \\
\text { mungkin menguatkan }\end{array}$ \\
\hline $2,4,6,8$ & $\begin{array}{l}\text { Nilai-nilai antara dua } \\
\text { nilai pertimbangan yangberdekatan }\end{array}$ & $\begin{array}{l}\text { Nilai ini diberikan bila ada dua kompromi di antara } \\
\text { dua pilihan }\end{array}$ \\
\hline Kebalikan & \multicolumn{2}{|c|}{$\begin{array}{l}\text { Jika untuk aktivitas i mendapat satu angka dibanding dengan aktivitas } \mathrm{j} \text { maka } \mathrm{j} \text { mempunyai nilai } \\
\text { kebalikannya dibanding dengan } \mathrm{i}\end{array}$} \\
\hline
\end{tabular}

Sumber: Saaty (1994)

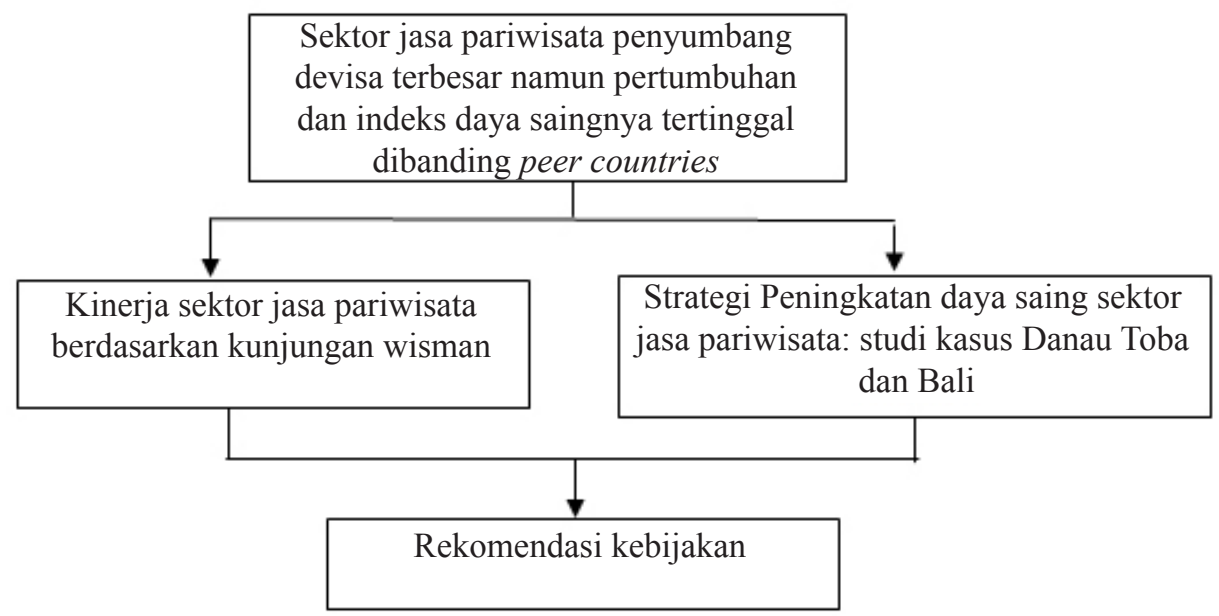

Gambar 2. Kerangka pemikiran penelitian 


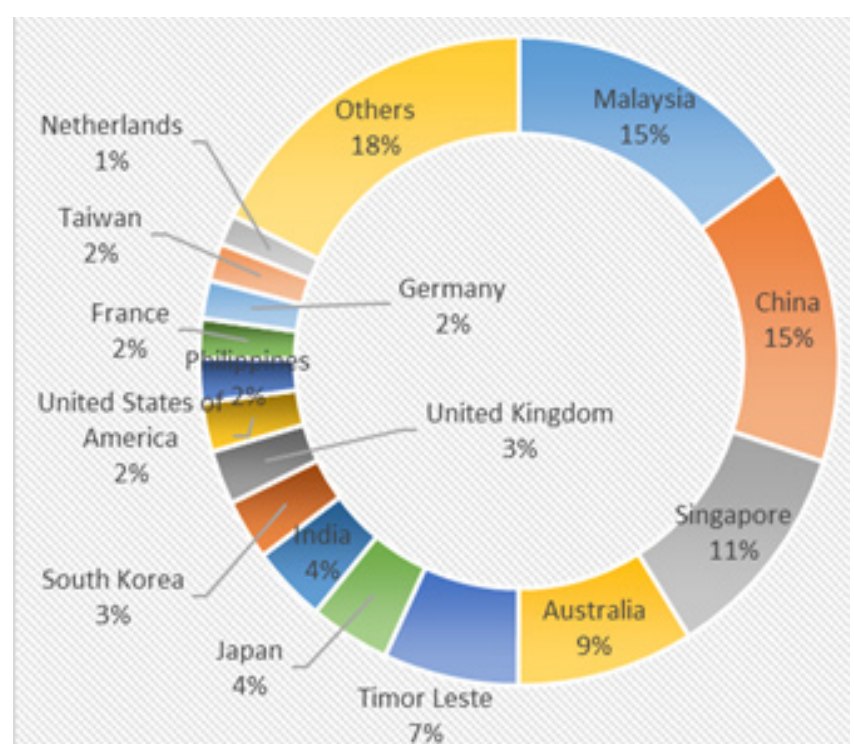

Gambar 3. Jumlah kunjungan wisatawan mancanegara ke Indonesia berdasarkan negara asal tahun 2017

Disamping negara di kawasan ASEAN dan Asia Pasifik lainnya, beberapa negara yang masuk ke dalam klasifikasi Top 15 negara dengan kunjungan wisatawan ke Indonesia tertinggi adalah negara Inggris, Amerika Serikat, Perancis, Jerman, dan Belanda. Berdasarkan kondisi eksisting tersebut, maka pemasaran pariwisata nasional telah diarahkan untuk meningkatkan kerjasama internasional kepariwisataan dan mendatangkan sebanyak mungkin kunjungan wisatawan mancanegara, mencakup pasar wisata kawasan (a) Asia Tenggara, (b) Australia dan Amerika, (c) Asia Pasifik, dan (d) Europe, Middle East dan Africa (EMEA).

\section{Strategi Peningkatan Daya Saing Sektor Jasa Pariwisata Indonesia}

Bali dipilih sebagai studi kasus pada penelitian ini karena merupakan provinsi yang paling sering dikunjungi turis asing (lebih dari 3,7 juta) disusul DKI Jakarta, DIY, Jawa Timur, Jawa Barat, Sumatera Utara, Lampung, Sulawesi Selatan, Sumatera Selatan, Banten dan Sumatera Barat. Selain Bali yang merupakan destinasi utama wisman berkunjung ke Indonesia, Sumatera Utara dipilih sebagai lokasi survei karena representatif mewakili destinasi wisata Indonesia. Program Kabinet Kerja menetapkan sepuluh destinasi baru, yang dipopulerkan dengan istilah "10 Bali Baru" memasukkan Danau Toba di antara 9 destinasi wisata baru Indonesia lainnya. Danau yang terletak di Provinsi
Sumatera Utara ini memiliki keindahan yang tidak ada bandingannya. Danau Toba tercatat sebagai danau terbesar di Asia Tenggara karena wilayahnya mencakup 7 kabupaten yaitu Tapanuli Utara, Simalungun, Toba Samosir, Samosir, Dairi, Karo dan Humbang Hasundutan.

Metode analisis untuk menyusun strategi peningkatan daya saing jasa pariwisata Indonesia dengan studi kasus Danau Toba dan Bali adalah metode AHP. Pengambilan keputusan pemilihan strategi memiliki masalah yang kompleks, ditunjukkan dalam suatu struktur hirarki yang menunjukkan hubungan antara tujuan (goal) yaitu peningkatan daya saing sektor jasa pariwisata Indonesia, aktor, faktor dan alternatif strategi. Penyusunan strategi peningkatan daya saing jasa pariwisata Indonesia dimulai dari level aktor yang meliputi pelaku jasa usaha pariwisata (BIS), pemerintah (PEM), lembaga sertifikasi usaha pariwisata (SER), Perguruan Tinggi/ Sekolah Tinggi/Lembaga Bahasa (PT), dan sektor terkait dan pendukung. Pada level faktor, terdapat faktor-faktor yang harus menjadi pertimbangan di level masing-masing aktor dalam merumuskan strategi peningkatan daya saing jasa pariwisata seperti terlihat pada Gambar 4.

Pada tahap akhir, alternatif strategi dirumuskan meliputi 3 alternatif yaitu fasilitasi pemerintah dan sinergitas antara $\mathrm{K} / \mathrm{L}$, regulasi yang ramah dan penguatan infrastruktur pendukung pariwisata. Dalam hal ini, responden melakukan penilaian dengan teknik komparasi berpasangan (pairwise comparison) terhadap elemen-elemen pada suatu tingkat hirarki dengan memberikan bobot numerik. Penyebaran kuesioner dan FGD dilakukan di destinasi wisata Indonesia yaitu Sumatera Utara tepatnya Danau Toba dan Bali. Berikut uraian masing-masing level.

\section{Level Aktor}

Berdasarkan hasil pengolahan horizontal, hirarki kedua, peubah aktor merupakan identifikasi pelaku yang memiliki peran dalam kebijakan peningkatan daya saing jasa pariwisata. Peubah aktor tersebut yaitu Pelaku Jasa Usaha Pariwisata (BIS); Pemerintah (PEM); Lembaga Sertifikasi Usaha Pariwisata (SER); Perguruan Tinggi/Sekolah Tinggi/Lembaga Bahasa (PT); Sektor Terkait dan Pendukung (Sek). 


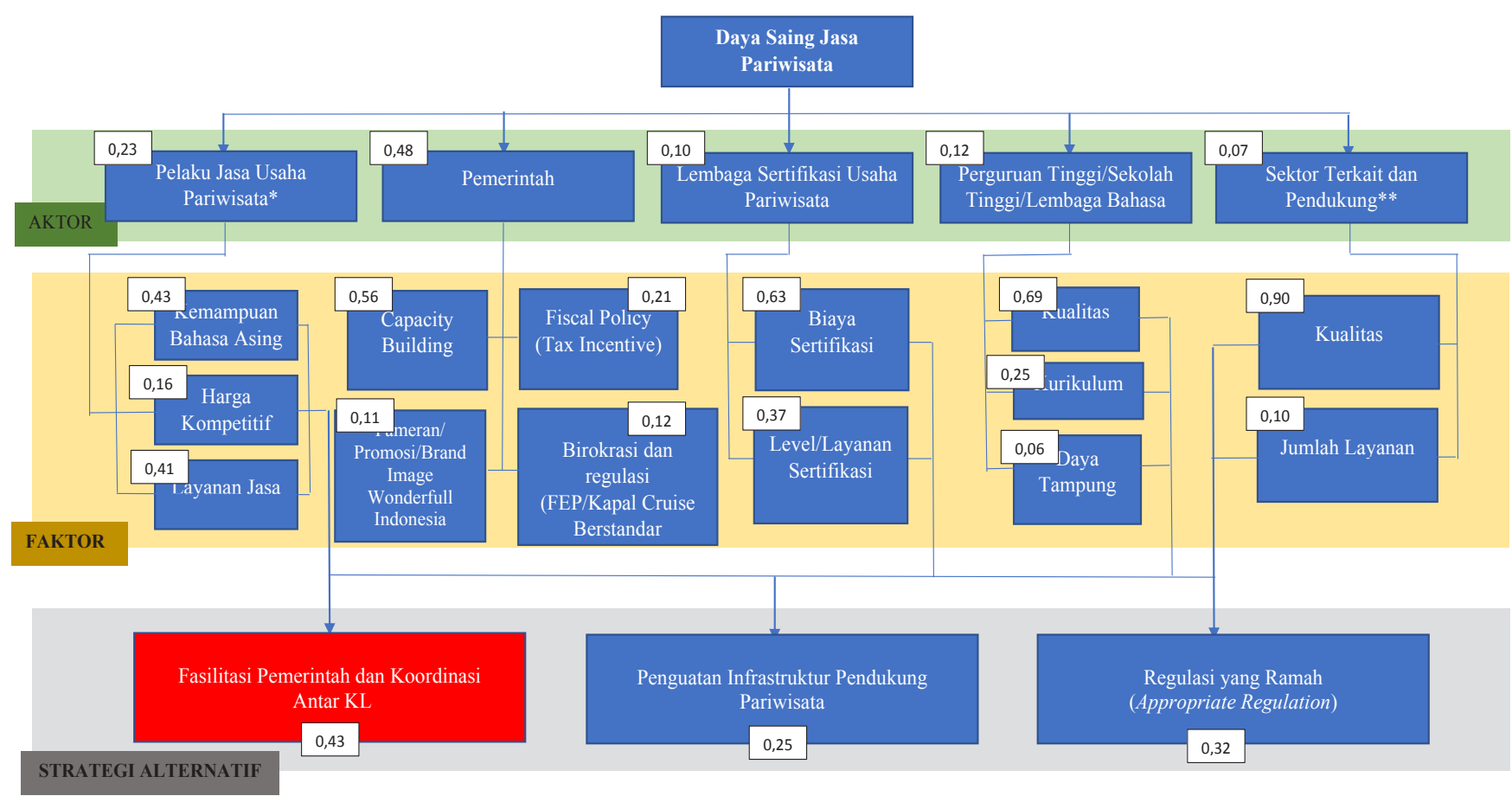

Gambar 4. Output hierarki keseluruhan untuk peningkatan daya saing subsektor pariwisata: studi kasus Danau Toba dan Bali

Hasil olahan AHP secara vertikal memberikan hasil yang sama (konsisten) dengan pengolahan secara horizontal. Secara vertikal hasil pengolahannya dapat disajikan pada Gambar 5. Hasil perbandingan aktor menunjukkan pemerintah memiliki peranan penting sebagai pelaku dalam kebijakan peningkatan daya saing jasa pariwisata. Aktor pemerintah memiliki bobot 0,485 . Sedangkan sektor terkait dan pendukung dianggap sebagai aktor yang paling kecil peranannya dalam penentuan kebijakan peningkatan daya saing jasa pariwisata yaitu dengan bobot sebesar 0,061 . Untuk meningkatkan daya saing jasa pariwisata, pemerintah memegang peranan penting sebagai penentu kebijakan yang akan diberlakukan terkait perkembangan jasa pariwisata. Kebijakan pemerintah pada jasa pariwisata akan memberikan dampak langsung dan tidak langsung para pengembangan sektor itu sendiri maupun sektor lain. Pemerintah bertanggung jawab atas empat hal utama, yaitu perencanaan (planning) daerah atau kawasan pariwisata, pembangunan (development) fasilitas utama dan pendukung pariwisata, pengeluaran kebijakan (policy) pariwisata, dan pembuatan dan penegakan peraturan (regulation).

Salah satu bentuk kebijakan di bidang pariwisata ini adalah adanya kebijakan pemerintah untuk mengembangkan pariwisata di danau Toba dengan membentuk Badan Otorita Pengelola Kawasan Pariwisata Danau Toba (Otorita Danau Toba). Otorita
Danau Toba dibentuk melalui Peraturan Presiden Nomor 49 Tahun 2016 (Perpres 49/2016) tentang Badan Otorita Pengelola Kawasan Pariwisata Danau Toba untuk melaksanakan pengembangan Kawasan Pariwisata Danau Toba sebagai Kawasan Strategis Pariwisata Nasional. Sesuai mandat yang tertuang pada Perpres 49/2016, Badan Pelaksana Otorita Danau Toba (BPODT) selaku Badan Pelaksana dari Otorita Danau Toba bermaksud untuk mengajukan penetapan sebagai Badan layanan Umum (BLU). Pembentukan Badan Otorita Pengelola Kawasan Pariwisata Danau Toba Undang-undang nomor 10 tahun 2009 tentang Kepariwisataan diatur bahwa pemerintah melakukan pembangunan kepariwisataan yang terdiri dari industri pariwisata, destinasi pariwisata, pemasaran, dan kelembagaan kepariwisataan.

Beberapa rencana dan langkah tindak lanjut pemerintah dalam hal ini Kementerian Pariwisata terkait pengembangan Danau Toba sebagai salah satu 10 destinasi wisata Indonesia adalah (1) Melaksanakan restorasi lingkungan Danau Toba, (2) Percepatan pembangunan destinasi pariwisata Danau Toba, (3) Perencanaan pengembangan taman bunga. Rencana calon Taman Bunga Danau Toba, dengan luas 453 Hektare berlokasi di Hutan Lindung Sijaba, Kabupaten Humbang Hasundutan. Sampai saat ini beberapa kegiatan terkait rencana Pembangunan Taman Bunga adalah sebagai berikut: 
1. Pada tanggal 8 November 2016 telah dilakukan koordinasi dengan Bapak Darmasto (Direktur Utama Taman Bunga Nusantara-TBN).

2. Sejak bulan Agustus, Dirut TBN telah secara intens berkoordinasi langsung dengan Menteri Lingkungan Hidup dan Sekretariat Negara untuk Visioning Concept dan juga deliniasi lahan.

3. Identifikasi awal: lahan di Kab Humbahas secara iklim dan jenis tanah cocok untuk lokasi Taman Bunga. Perlu kajian teknis lebih lanjut untuk memastikan hal tersebut, terutama terkait akses irigasi.

4. Konsep awal : pengembangan kawasan terintegrasi dengan initial program Taman Bunga $(+150 \mathrm{Ha})$, Pertanian dan Peternakan Terbuka (Ranch) serta industri pengolahan, dan juga Hotel \& Resort $(+10 \%)$. Pengelolaan kawasan akan melibatkan masyarakat.

Terkait dengan kebijakan tersebut, pemerintah harus melibatkan seluruh stakeholder baik industri yang terlibat di jasa pariwisata maupun masyarakat sekitarnya. Berdasarkan temuan lapang, masyarakat menganggap belum banyak dilibatkan dalam pengembangan kawasan pariwisata Danau Toba. Terkait dengan pengembangan pariwisata di Danau Toba, pengembangan wisata di Bali bisa dijadikan benchmark (dengan tetap mempertahankan nilai-nilai luhur dan budaya Sumatera). Sebagaimana masyarakat Bali, masyarakat Danau Toba harus merasakan multiplier effect dari kemajuan pariwisata di daerah/wilayahnya. Dampak kemajuan daerah karena berkembangnya jasa pariwisata di Bali telah dirasakan di seluruh lapisan masyarakat Bali sehingga tidak terjadi perbenturan antar kebijakan pemerintah dengan keinginan masyarakat.

\section{Priorities with respect to: Daya Saing Jasa Pariwisata}

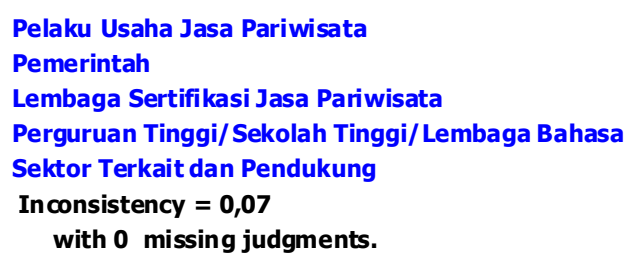

\section{Level Faktor}

Hierarki kedua adalah Peubah Faktor, yaitu identifikasi faktor-faktor penentu model pengambilan keputusan para aktor (level aktor) untuk strategi peningkatan daya saing jasa pariwisata. Peubah faktor tersebut, yaitu kemampuan berbahasa asing, harga kompetitif, layanan jasa capacity building, pameran/promosi, birokrasi dan regulasi, fiscal policy, biaya sertifikasi, jumlah level sertifikasi, kualitas Perguruan Tinggi, kurikulum Perguruan Tinggi, daya tampung Perguruan Tinggi, kualitas sektor pendukung, jumlah layanan pendukung. Pada aktor pelaku jasa usaha pariwisata terdapat 3 faktor penentu, yaitu kemampuan berbahasa asing, harga kompetitif, dan layanan jasa.

Berdasarkan Gambar 6, hasil perbandingan faktor menunjukkan bahwa kemampuan bahasa Inggris merupakan elemen penting dalam penentuan strategi kebijakan peningkatan daya saing jasa pariwisata. Faktor ini memiliki bobot tertinggi, yaitu 0,433 . Selanjutnya, faktor layanan jasa merupakan faktor kedua terbesar (bobot sebesar 0,412), dan terakhir adalah faktor harga yang kompetitif (bobot sebesar 0,155). Hal ini menunjukkan bahwa kemampuan berkomunikasi bahasa asing seperti bahasa Inggris atau Mandarin dan layanan yang baik (baik tangible maupun yang intangible) adalah faktor kunci dalam menilai kinerja pelaku usaha jasa pariwisata. Kemudahan berkomunikasi dan pelayanan yang baik akan meningkatkan pentingnya peranan para pelaku jasa usaha jasa pariwisata. Sedangkan harga bukan menjadi faktor penting karena jasa pariwisata bukan termasuk barang normal, dimana kenaikan harga tidak menyebabkan permintaan mengalami penurunan. Kepuasan terhadap jasa pariwisata yang dihasilkan menjadi hal terpenting. Temuan bahwa kemampuan berbahasa Inggris ini meningkatkan daya saing sektor jasa pariwisata sejalan dengan hasil studi Testiana et al. (2016) untuk kasus Desa wisata Kandri Semarang.

Gambar 5. Susunan bobot dan prioritas hasil pengolahan vertikal antar elemen pada level aktor 
Selanjutnya, terdapat 4 faktor penentu bagi pemerintah dalam strategi kebijakan peningkatan daya saing jasa pariwisata, yaitu capacity building, pameran/promosi, birokrasi dan regulasi, dan fiscal policy. Berdasarkan hasil perbandingan faktor capacity building merupakan elemen penting dalam penentuan strategi kebijakan peningkatan daya saing jasa pariwisata pada aktor pemerintah. Faktor ini memiliki bobot tertinggi, yaitu 0,561. Faktor fiscal policy merupakan faktor kedua terbesar (bobot sebesar 0,212), dan faktor birokrasi dan regulasi merupakan faktor ketiga terbesar (bobot sebesar 0,118) dan terakhir adalah faktor promosi (bobot sebesar 0,109). Secara lengkap dapat dilihat pada Gambar 7.
Selanjutnya berdasarkan Gambar 8, aktor lembaga sertifikasi jasa pariwisata memiliki 2 faktor yang berperan penting dalam penyusunan strategi peningkatan daya saing jasa pariwisata yaitu biaya sertifikasi dan layanan sertifikasi. Biaya sertifikasi merupakan elemen penting dalam penentuan strategi kebijakan peningkatan daya saing jasa pariwisata. Faktor ini memiliki bobot tertinggi, yaitu 0,631. Selanjutnya, faktor jumlah level atau layanan sertifikasi merupakan faktor kedua terbesar (bobot sebesar 0,369).

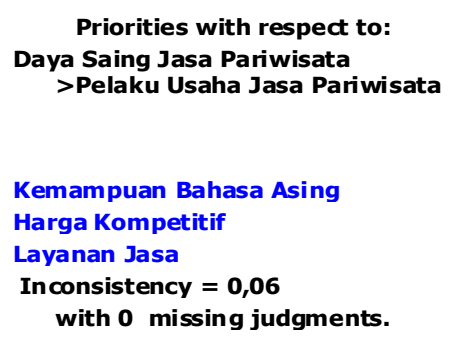

Gambar 6. Susunan bobot dan prioritas hasil pengolahan vertikal antar elemen faktor pada level aktor pelaku usaha jasa pariwisata
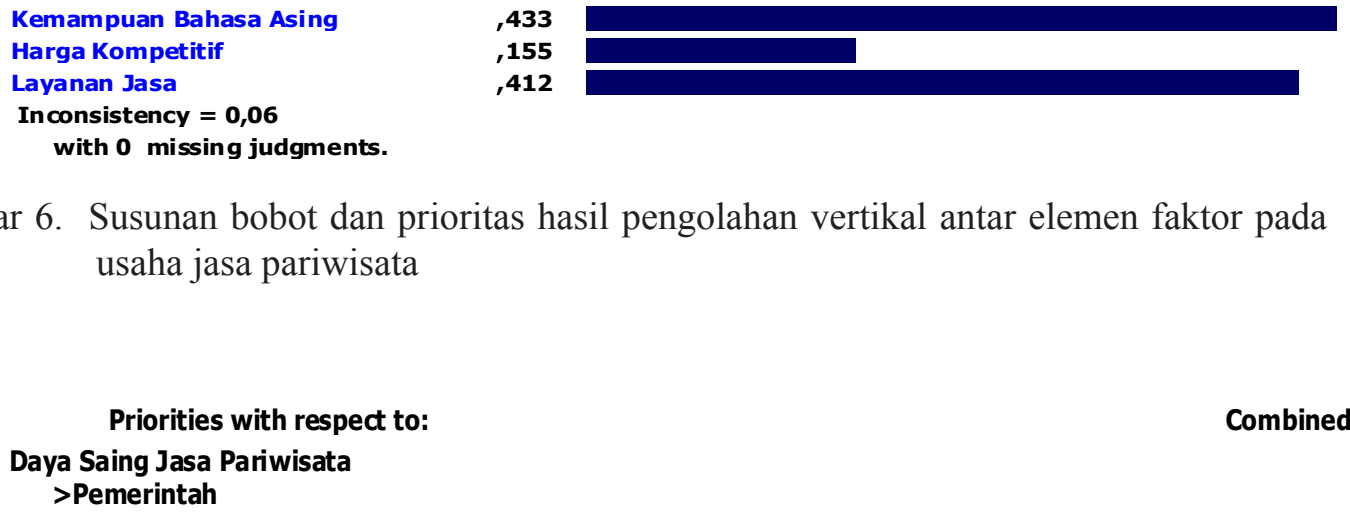

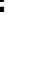


Hal ini menunjukkan bahwa kemampuan biaya sertifikasi merupakan faktor kunci yang mendorong lembaga sertifikasi jasa pariwisata berperan dalam meningkatkan daya saing jasa pariwisata. Dibandingkan dengan layanan, biaya menjadi faktor yang lebih penting dalam meningkatkan daya saing jasa pariwisata. Biaya sertifikasi jasa pariwisata yang diharapkan adalah yang sesuai kemampuan para pelaku usaha.

Menurut aktor Perguruan Tinggi/Sekolah Tinggi/ Lembaga Bahasa, terdapat 3 faktor yang berperan penting dalam penentuan strategi kebijakan peningkatan daya saing jasa pariwisata yaitu kualitas, kurikulum, dan daya tampung Perguruan Tinggi. Hasil perbandingan faktor pada Perguruan Tinggi/Sekolah Tinggi/Lembaga Bahasa menunjukkan bahwa kualitas lembaga tersebut merupakan elemen penting dalam penentuan strategi kebijakan peningkatan daya saing jasa pariwisata. Faktor ini memiliki bobot tertinggi, yaitu 0,693. Selanjutnya faktor kurikulum yang dimiliki oleh lembaga tersebut merupakan faktor kedua terbesar (bobot sebesar 0,252), dan faktor terakhir adalah daya tampung (bobot sebesar 0,055). Hal ini menunjukkan bahwa kualitas lembaga merupakan faktor kunci yang mendorong peran Perguruan Tinggi/ Sekolah Tinggi/Lembaga Bahasa dalam meningkatkan dayasaing jasa pariwisata. Berkembangnya lembaga Perguruan Tinggi/Sekolah Tinggi/Lembaga Bahasa yang bergerak di bidang jasa pariwisata menyebabkan daya tampung tidak menjadi persoalan yang dihadapi para lembaga tersebut, sebaliknya kualitas lembaga tersebut menjadi faktor yang banyak diperhatikan dan penting bagi para pelaku usaha jasa perdagangan. Temuan bahwa faktor Sumber Daya Manusia (SDM) berpengaruh terhadap daya saing jasa pariwisata sejalan dengan temuan Rahayu et al. (2015). Dengan menggunakan pendekatan 7P (price, place, promotion, people, process and physical evidence), Rahayu et al. (2015) menyatakan bahwa unsur People, berpengaruh terhadap kedatangan turis di Kota Bandung. Gambar 9 menyajikan hasil pengolahan secara vertikal bobot dan prioritas keempat faktor.

Pada faktor sektor terkait dan pendukung dalam strategi kebijakan peningkatan daya saing jasa pariwisata, terdapat 2 faktor, yaitu kualitas sektor pendukung dan jumlah layanan sektor pendukung. Berikut Gambar 10 dijabarkan hasil pengolahan secara vertikal bobot dan prioritas keempat faktor. Hasil perbandingan faktor pada sektor terkait dan pendukung menunjukkan bahwa kualitas lembaga tersebut merupakan elemen penting dalam penentuan strategi kebijakan peningkatan daya saing jasa pariwisata. Faktor ini memiliki bobot tertinggi, yaitu 0,896. Selanjutnya, faktor jumlah layanan dari lembaga tersebut merupakan faktor kedua terbesar (bobot sebesar 0,104). Dalam peningkatan daya saing jasa pariwisata dibutuhkan keterlibatan berbagai sektor terkait dan pendukung kegiatan jasa pariwisata. Sektor yang terkait dengan jasa pariwisata sangatlah luas diantaranya sektor perdagangan, asosiasi perhotelan dan restoran, travel, asosiasi pengusaha di bidang jasa, pelabuhan, bandara, sektor jasa perbankan dan industri kuliner. Dukungan industri kuliner, biro perjalanan, hotel dan restoran dalam peningkatan daya saing jasa pariwisata sejalan dengan temuan Tenges (2016) untuk kasus Kota Manado dan Bhuiyan et al. (2014).

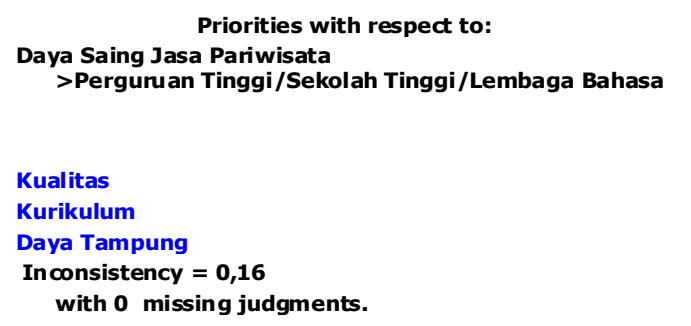

Combined

,693

, 252

055 with 0 missing judgments.

Gambar 9. Susunan bobot dan prioritas hasil pengolahan vertikal antar elemen faktor pada level aktor PT/ST/ lembaga bahasa jasa pariwisata 


\section{Alternatif Strategi}

Hasil AHP untuk level alternatif strategi menunjukkan bahwa fasilitas pemerintah dan sinergitas antar KL merupakan strategi tertinggi dalam peningkatan dayasaing jasa pariwisata dengan bobot, yaitu 0,430. Hal ini sesuai dengan temuan dalam FGD, bahwa pemerintah merupakan aktor terpenting dan sinergi antar lembaga di bidang jasa pariwisata merupakan hal yang paling penting dalam meningkatkan dayasaing jasa pariwisata. Berikut ini dijabarkan hasil alternatif strategi peningkatan dayasaing jasa pariwisata secara vertikal bobot dan prioritas keempat faktor.

Berdasarkan Gambar 11 diketahui bahwa prioritas strategi peningkatan daya saing jasa pariwisata adalah fasilitasi pemerintah dan sinergitas antara K/L (dengan bobot sebesar 0,430). Prioritas strategi kedua yaitu regulasi yang ramah (bobot sebesar 0,319) dan strategi terakhir adalah penguatan infrastruktur pendukung pariwisata (bobot sebesar 0,251). Temuan ini sejalan dengan studi Weldearega (2017) yang menyatakan bahwa infrastruktur seperti hotel, bandara udara, kualitas jalan raya, internet dan telephone, situs-situs budaya, stadium olahraga, bahkan sampai dengan kualitas lingkungan memengaruhi daya saing pariwisata. Dengan menggunakan metode SWOT, penelitian Wijayanti et al. (2015) menunjukkan bahwa kemudahan akses transportasi juga menjadi strategi pemasaran untuk meningkatkan daya saing pariwisata agrotourism di Kabupaten Jember. Penelitian Budi (2015) mendukung temuan penelitian ini bahwa fasilitas dan infrastruktur memengaruhi daya saing jasa pariwisata di Kota Jakarta.

Strategi terkait kebijakan yang lebih ramah diantaranya berupa kebijakan visa bagi turis mancanegara. OECD (2014) menyatakan bahwa salah satu bentuk fasilitasi perdagangan pada sektor jasa pariwisata adalah dengan pemberian visa bagi turis mancanegara. Beberapa fasilitasi terkait visa seperti proses pengurusan, biaya dan persyaratan visa. Besarnya biaya visa memengaruhi turis asing masuk. Studi Pam et al. (2018) menunjukkan bahwa perubahan biaya visa turis China ke Australia memengaruhi daya saing jasa pariwisata. Bahkan studi ini menunjukkan peningkatan pendapatan dari biaya visa tidak mengkompensasi dampak ekonomi yang negatif dari berkurangnya kedatangan turis China ke Australia.
Priorities with respect to:

Daya Saing Jasa Pariwisata >Sektor Terkait dan Pendukung
Combined

896

, 104

Jumlah Layanan

Inconsistency $=\mathbf{0}$, with 0 missing judgments.

Gambar 10. Susunan bobot dan prioritas hasil pengolahan vertikal antar elemen faktor pada level aktor sektor terkait dan pendukung jasa pariwisata

\section{Synthesis: Summary}

Combined instance -- Synthesis with respect to:

Daya Saina Jasa Pariwisata.

Overall Inconsistency $=, 10$

Fasilitas Pemerintah dan Sin erqitasAnatr KL

Penquatan Inftrastruktur Pendukung Pariwisate .251

Requlasi yanq Ramah (Appropriote Requlation) .319

Gambar 11. Susunan bobot dan prioritas hasil pengolahan horizontal antar elemen pada level alternatif strategi 


\section{Implikasi Manajerial}

Pemerintah baik pusat maupun daerah serta antar $\mathrm{K} / \mathrm{L}$ sinergi dalam berbagai kebijakan. Perlu mapping terhadap regulasi yang menghambat daya saing jasa pariwisata serta sektor terkait dan pendukung lainnya. Salah satu kebijakan yang berdampak positif bagi peningkatan daya saing jasa pariwisata adalah kebijakan bebas visa kunjungan dari 45 negara menjadi 90 negara dan bertambah kembali menjadi 169 negara. Kebijakan ini harus didukung dengan kebijakan lainnya seperti tersedianya layanan jasa angkutan udara dengan harga kompetitif maupun strategi branding. Selain itu, diperlukan peningkatan infrastruktur di sekitar tempat wisata dan tempat akomodasi dan berbagai infrastruktur pendukung lainnya seperti money changer, tourist information centre, dan konektivitas internet.

Pelaku usaha harus meningkatkan pelayanan jasanya untuk turis. Tidak hanya hospitality (ramah tamah), kemampuan akan penguasaan bahasa asing dan bahkan sertifikasi kompetensi di sektor jasa pariwisata di jasa sangat diperlukan untuk peningkatan daya saing jasa pariwisata.

\section{KESIMPULAN DAN SARAN}

\section{Kesimpulan}

Sektor jasa pariwisata Indonesia merupakan sektor yang memiliki nilai ekspor jasa terbesar dengan tren yang terus meningkat. Namun demikian, tren pertumbuhan ekspornya relatif rendah. Negara mitra utama Indonesia di sektor jasa pariwisata didominasi oleh negara di kawasan ASEAN dan Asia Pasifik lainnya seperti Malaysia, China, Singapura, Australia, Timor Leste, Jepang, India, dan Korea Selatan. Selain itu, negara mitra lainnya yang masuk termasuk kedalam Top 15 adalah Inggris, Amerika Serikat, Perancis, Jerman, dan Belanda. Prioritas strategi peningkatan dayasaing jasa pariwisata Indonesia adalah pertama, fasilitasi pemerintah dan sinergitas antara K/L. Kedua, regulasi yang ramah. Ketiga, strategi penguatan infrastruktur pendukung pariwisata.

\section{Saran}

Terkait hasil penelitian, implikasi kebijakan dan bisnis untuk strategi peningkatan daya saing jasa pariwisata Indonesia dengan studi kasus jasa pariwisata di Danau
Toba dan Bali adalah sebagai berikut: Penciptaan kondisi politik, keamanan, ekonomi, dan iklim usaha yang kondusif, baik di level daerah maupun nasional. Kondisi politik dan ekonomi yang stabil merupakan determinan utama dayasaing ketiga sektor jasa yang dianalisa. Potensi munculnya konflik-konflik horizontal dan vertikal di masyarakat Indonesia sangatlah besar. Keberagaman masyarakat Indonesia dalam hal suku, etnis, dan agama yang dikombinasikan dengan otonomi daerah dapatmenjadipemicumunculnyaketidakstabilan politik dan keamanan. Terkait dengan kondisi ekonomi, pemerintah perlu menjamin sinkronisasi dan koordinasi kebijakan antara Kementerian dan Lembaga $(\mathrm{K} / \mathrm{L})$ Pemerintah. Regulasi-regulasi yang dikeluarkan $\mathrm{K} / \mathrm{L}$ harus sejalan dan tidak tumpang tindih. Semua pejabat pemerintah baik di level pusat maupun daerah harus satu suara untuk setiap kebijakan yang dikeluarkan. Hal tersebut akan menimbulkan ketenangan dan keyakinan para pelaku usaha dan maupun wisatawan mancanegara untuk berkunjung ke Indonesia.

Penyediaan infrastruktur utama dan pendukung yang mumpuni dalam menunjang ekspor jasa Indonesia. Hasil studi ini secara jelas menunjukkan bahwa infrastruktur yang memadai merupakan syarat mutlak yang dibutuhkan dalam pengembangan ekspor jasa pariwisata Indonesia. Infrastruktur yang dimaksud mencakup infrastruktur bandara dan pelabuhan yang menjadi "main gate" masuknya turis ke Indonesia, akses dari bandara/pelabuhan ke lokasi wisata dan tempat akomodasi (konektivitas multimoda), infrastruktur di dalam tempat wisata, infrastruktur di sekitar tempat wisata dan tempat akomodasi, dan berbagai infrastruktur pendukung lainnya, seperti money changer, tourist information centre, konektivitas internet dan sebagainya. Selanjutnya, Penguatan pelaku usaha (pebisnis) yang bergerak di sektor jasa pariwisata. Penguatan usaha bagi pebisnis dari sisi sertifikasi, penguasaan bahasa asing, kemampuan melayani dan memiliki keramahtamahan (hospitality).

\section{DAFTAR PUSTAKA}

Aulia A, Farah. 2019. Model of tourism destination development tegal case study, Central Java. Jurnal Hospitality dan Pariwisata 5(1).

Bank Indonesia. 2018. Statistik Ekonomi dan Keuangan Indonesia (SEKI). www.bi.go.id/statistic/seki/ terkini/eksternal/contents/default.aspx[ $20 \mathrm{Feb}$ 2018]. 
BPS. 2018. Statistik Indonesia 2018. Jakarta: BPS.

Bhuiyan MAH, Chamhuri S, Mohamad IS, Rabiul I. 2014. The role of government for ecotourism development: focusing on east coast econimic region. Jurnal of Social Science 7(4): 557-564. https://doi.org/10.3844/jssp.2011.557.564.

Budi SP. 2015. Model Struktural Pengembangan Daya Saing Destinasi Wisata Studi Kasus Kota Jakarta. University Research Colloquium.

Hareen ZTG. 2016. Analisis potensi pengembangan pariwisata pendekaran ahp pada jenis objek wisata alam, wisata budaya, dan wisata alternatif di Kabupaten Bojonegoro. Swara Bhumi e-Journal Pendidikan Geografi FIS Unesa 1(2).

ITAPS, BI. 2016. Kajian Potensi dan Peluang Perdagangan Barang dan Jasa di Provinsi Riau dalam Menghadapi Masyarakat Ekonomi ASEAN (MEA). Laporan penelitian.

Molinar ACM, Sosa FAP, Ochoa-Llamas I, Moncada Jimenez P. 2017. The Perception of Destination Competitiveness by Tourists. Investigaciones Turisticas (14): 1-20. http://dx.doiorg/10.14461/ INTURI2017.14.01.

Masruroh, Nurhayati. 2016. Strategi pengembangan pariwisata dalam rangka peningkatan pendapatan asli daerah Kabupaten Kuningan. https://media. neliti.com/media/publications/171855-IDstrategi-pengembangan-pariwisata-dalam-r.pdf. [5 Okt 2019].

OECD. 2014. Travel, Tourism and Growth. OECD Tourism Trends and Policies 2014.

Pambudi AS, Ketut BYB. 2018. Sistem penunjang keputusan tujuan wisata air terjun di kota bogor menggunakan metode ahp. Sinkron Jurnal dan Penelitian Teknik Informatika 2(2).

Prasetyaningrum PT, Sari A. 2019. Penerapan analytical hierarchy process (AHP) untuk mendukung keputusan pemilihan destinasi tempat wisata daerah istimewa yogyakarta untuk para wisatawan mancanegara non asia. Simetris Jurnal Teknik Industri, Mesin, Elektro dan Ilmu Komputer 2(10).

Pusat Penelitian Badan Keahlian DPR. 2016. Prospek danStrategiIndonesiaMenghadapiImplementasi Masyarakat Ekonomi ASEAN. Jakarta: PT Balai Pustaka.

Rahayu I, Dodik RN, Achmad F. 2015. Marketing mix analysis of natural tourism area "kawah putih" and its effect on visitor's decision. Indonesian Journal of Business and Entrepreeurship (IJBE) $1(2)$.

Saaty TL. 1994. Pengambilan Keputusan Bagi Para Pemimpin. Penerjemah: Liana Setiono. Jakarta: PT. Pustaka Binaman Pressindo.

Sabahan Y. 2017. Kajian daya saing sektor pariwisata Kabupaten Sambas. Jurnal Akutansi, Ekonomi, dan Manajemen 5(2):274-278. https://doi. org/10.30871/jaemb.v5i2.492.

Stankova M, Ivanka V. 2017. Tourism destination competitiveness models. Journal Tourism and Travelling 1(1): 58-64. https://doi.org/10.21511/ tt.1(1).2017.06.

Tenges. 2016. Identifikasi Klaster pariwisata untuk peningkatan daya saing kota manado (studi kasus: industri pariwisata kuliner wakeke). Jurnal Berkala Ilmiah Efisiensi 16(2).

Testiana D.W., Dodi M dan Akhmad F. 2016. Peningkatan kemampuan berbahasa inggris dan manajemen pemasaran melalui web bagi pemilik Homestay Desa Wisata Kandri Semarang. Jurnal Abdimas 20(2):61-65.

Wijayanti T, Musa H dan Muksin. 2015. Marketing strategies for developing agrotourism in Jember Regency. Indonesian Journal of Business and Entrepreeurship (IJBE) 1(3):148-157. https:// doi.org/10.17358/IJBE.1.3.148.

World Economic Forum. 2017. The Travel \& Tourism Competitiveness Report 2017. Geneva:WEF. 